\title{
The Use of Financial Information: A Case of Ignorance from Lebanese Banks
}

\author{
Hassan Ibrahim Rkein1* \& Ali Rkein2 \\ ${ }^{1}$ Faculty of Business Administration, Accounting Department, Al Maaref University, Lebanon. \\ ${ }^{2}$ Asia Pacific College of Business and Law, Charles Darwin University, Australia
}

\begin{abstract}
:
Accounting is a financial information system that intends to provide users with useful financial information about reporting entities. The conceptual framework of accounting in its latest version in 2018 has stressed that for the financial information to be useful it must satisfy certain criteria that comprise relevance, faithful representation, verifiability, timeliness, comparability and understandability. Banks are ones of many reporting entities that are required to prepare their financial statements in accordance with the International Financial Reporting Standards (IFRS) and obtain guidance from the Conceptual Framework on all other situations that IFRS doesn't not cover. In addition, bank clients are considered to be some of the users who rely on banks financial reports to supposedly make informed decisions in their dealings with the banks. This research, however, aims to examine the use of financial information by bank clients. And to assess the extent to which they have adjusted their decisions based on the financial information reported by banks. The research focuses on the Lebanese banks as a case study. This comes at times when the banking sector in Lebanon has suddenly become incapacitated and insolvent after it has always been thought of as productive, successful and highly resilient. Hence, this research aims to examine whether bank clients in Lebanon have in any way adjusted their dealings with banks or they acted in ignorance.

Therefore, this research collected information from Bank account holders who are either individuals and/or small Businesses. The distribution of participant were 50 businesses and 70 well educated individuals. Businesses were owners of small Accounting firms, all of these owners are members of the Lebanese Certified Practiced Accountants (LCPA) syndicate in Lebanon (Data was collected through a survey based questionnaire.

Since the definition of the Objective of Financial Reporting in the Conceptual Framework is "to provide financial information about the reporting entity that is useful to existing and potential investors, lenders and other creditors in making decisions relating to providing resources to the entity", this research raises concerns regarding the validation of the qualitative characteristics of Financial information. And therefore it proposes a different way of reporting financial information to users of Banks' financial information.
\end{abstract}

Keywords: Bank creditors, financial reporting, conceptual framework, accounting firms, Lebanon. 